Editorial 


\title{
Antonio Candido, no tempo da delicadeza
}

\author{
Márcia Marques de Morais*
}

\begin{abstract}
Resumo
Este texto, à guisa de Editorial, tem três objetivos. No primeiro momento, pretende historiar, com brevidade, o surgimento do projeto de organizar esta edição 49 da Revista SCRIPTA, em homenagem a Antonio Candido, com textos que privilegiassem três eixos do trabalho do intelectual: o Professor, o Crítico, o Político, e constata o imbricamento dessas três vertentes na vida e produção intelectual do homenageado. Para além dessa constatação, registra enfaticamente o afeto que permeia suas experiências, seus testemunhos, sua convivência e sua escrita. Em um segundo momento, apresenta, muito sucintamente, os artigos selecionados para a publicação, bem como as entrevistas e textos a que se chamou "Do afeto". Em seguida, vale-se da oportunidade de relatar duas experiências pessoais com Antonio Candido que evidenciam a "reversibilidade" entre literatura e vida. Para tanto, vale-se de ensaio do autor sobre jagunços mineiros ("Jagunços mineiros: de Cláudio a Guimarães Rosa"), cuja exposição - escrita a partir de aulas e palestras em curso ministrado na USP -, enlaça, afetuosamente, vida e literatura.
\end{abstract}

Palavras-chave: Antonio Candido: vida e obra. Humanismo. Testemunho.

* Pontifícia Universidade Católica de Minas Gerais - PUC Minas. Doutora em Teoria Literária e Literatura Comparada pela Universidade de São Paulo - USP. 


\section{Antonio candido, in the time of delicateness}

\section{ABSTRACT}

This text, by way of Editorial, has three goals. In the first moment, it intends to briefly contextualize the project of organizing this 49th issue of SCRIPTA, in honour of Antonio Candido, with texts that favoured three axes of his intellectual work: The Teacher, The Critic, The Political, pointing to the interweaving of these three aspects into his life and intellectual production. Beyond this evidence, it emphatically records the affect that permeates his experiences, testimonies, conviviality and writing. In a second moment, it presents, very succinctly, the papers that were selected for publication, as well as interviews and texts organized under a section called "Of Affection". Next, it gives an account of two personal experiences with Antonio Candido that highlight the "reversibility" between life and literature. For this purpose, it draws on the Candido's essay about the jagunços of Minas ("Jagunços Mineiros: De Cláudio a Guimarães Rosa"), whose writing - took from classes and lectures given at USP -, affectionately intertwines life and literature.

Keywords: Antonio Candido: life and work. Huminsm. 
Esta nossa SCRIPTA, edição 49, nasce da ideia e do coração da PUC Minas, especialmente do Programa de Pós-graduação em Letras e do Centro de Estudos Luso-afro-brasileiros (CESPUC), de homenagear, com um número de sua Revista, Antonio Candido, que nos deixou em 2017, permanecendo indelevelmente entre nós, com suas lições de "sala de aula", sua crítica e, mais ainda, com suas lições de vida. Cientes de que homenagens como esta já foram e o são constantes e múltiplas nos meios universitário e jornalístico, ainda assim, estamos convencidos de que sempre haverá motivos para "matéria de memória" e matéria de divulgação da trajetória de um sujeito exemplar, tanto em relação ao trabalho que realizou quanto em relação às ideias que defendeu e sobre as quais nos faz refletir.

Para dar corpo a este trabalho, a Editoria da SCRIPTA convidou como colaboradora a professora Adélia Bezerra de Meneses (USP/UNICAMP) e a mim, para trabalharmos juntas em função da publicação deste número da Revista.

Passamos, assim, ao planejamento inicial dela, pensando em solicitar artigos que se organizassem em torno de três eixos de abordagem - Antonio Candido: o Professor; o Crítico; o Político -, sabendo, de antemão, que a própria vida em sua inteireza e integridade se incumbe de entretecer essas direções.

$\mathrm{O}$ convite à Professora Adélia, prontamente aceito como amiga, discípula e ex-orientanda do professor Antonio Candido, foi imprescindível a esta edição que agora vem a público. Sua história com e ao lado de Candido, bem como seus contatos e convívio com pessoas do meio universitário e extramuros universitários, deram à Revista uma outra e nova feição, relativamente à homenagem desejada pelo Programa de Pósgraduação em Letras da PUC Minas e pelo CESPUC. O afeto, 
inerente às manifestações sobre Antonio Candido e/ou sua obra, passou, ele mesmo, a figurar ou como um quarto eixo, ou, mais ainda, como amálgama entre textos.

Adélia, a partir de agora, referida sem as formalidades convencionais, por ser, ela mesma, parte desse afeto, não assina comigo este editorial, meio torto como gênero, pois preferiu assinar o texto que abre esta SCRIPTA, texto que garimpou, obteve permissão quanto aos direitos autorais para torná-lo público e comentou, contextualizando-o neste momento político grave por que passa o Brasil, já dando, de início, um dos tons talvez o mais grave! -, solicitados ao leitor desta SCRIPTA.

Esse texto conversará com outros no interior da Revista, enlaçando-os e evidenciando o eixo Antonio Candido, Político: nessa vertente se poderá ler a entrevista de Antonio Candido ao jornal Brasil de Fato, cuja licença para republicação foi obtida também pela incansável colaboradora, que conseguiu sua liberação para publicação em revista. Como se não bastasse, é ainda da lavra de Adélia a pesquisa por imagens que viessem a dar ainda mais visibilidade às questões políticas tratadas pelos textos de Candido (perceba-se, na ilustração do artigo, foto liberada por Sebastião Salgado) bem como as fotos de seu arquivo pessoal que dão mais luz, mais brilho - ilustram - as matérias a que chamamos "Do Afeto": depoimentos, memórias, gratidão de Antonio Arnoni Prado (UNICAMP); Roberto Gambini (psicanalista); Frei Betto (Carlos Alberto Libânio Christo); Antonio Carlos Fester (Comissão de Justiça e Paz/ Educador em Direitos Humanos); Ligia Chiappini (USP/Freie Universität Berlin) e Walnice Nogueira Galvão (USP).

Voltando ao eixo político, ao lado da matéria do Jornal Brasil de Fato, vamos encontrar artigo sobre o gênero entrevista 
como possibilidade de leitura do perfil do entrevistado, no caso, um Antonio Candido em sua própria enunciação; ainda se poderá ler outra entrevista em que Candido é o entrevistado sobre um escritor de Poços de Caldas, uma das cidades do coração, para onde se mudou aos dez anos e meio de idade.

Assim, percebidas essas duas vertentes dos textos desta Revista - a política e a afetiva, organizadas em dois eixos ("De entrevistas" e "Do afeto") que se imbricam, misturam-se, como é próprio da vida real -, passamos à seção que nos apresentará artigos sobre leituras de ficção e crítica literária de autoria de Antonio Candido, ou nelas inspiradas. A essa seção intitulouse "De leituras e críticas", inaugurada com o texto inédito do Mestre, "Martírio e Redenção", comentado por Adélia, como já se adiantou.

O texto seguinte privilegia Antonio Candido, professor que se "escuta" (realço) em Na sala de aula e militante, a pregar, propagar $\mathbf{O}$ direito à literatura. Essa ordenação teve um propósito, bem institucional e político - é também o da luta da PUC Minas quanto ao direito à sala de aula e, nela, a leitura transformadora da literatura, da poesia.

Seguem-se textos que, dialogando com a crítica de Candido, têm cada um deles sua inclinação: a leitura em uma vertente psicanalítica, de poemas de Drummond (Cleusa Rios P. Passos); uma leitura "recortando" a obra Recortes (CANDIDO, 1993), que reúne ensaios do Crítico (Letícia Malard); o diálogo entre Mário de Andrade e Antonio Candido quanto a aspectos críticos (Edu Teruki Otsuka); uma leitura "historiográfica" apoiada no marco fundador com que Candido nos brindou em Formação da literatura brasileira: momentos decisivos (Maria Célia Leonel e José A. Segatto); um diálogo crítico entre Angel Rama 
e Antonio Candido (Ney A. G. Canani); a apresentação de lições do mestre, evidenciando questões de tradução de textos de Antonio Candido (Marcel Vejmelkma); uma " conversa" entre A. Candido e Roberto Schwarz sobre leituras de Alencar (Ana Karla Canarinos), e uma leitura de novela de Guimarães Rosa, inspirada no trabalho crítico de Antonio Candido (Simone Guimarães Matheus).

Esta é a nossa SCRIPTA, homenagem a Antonio Candido que ora é oferecida à leitura do público leitor de ficção, de crítica literária, comprometido com a função transformadora da literatura, um dos direitos fundamentais do ser humano.

No entanto, este texto pretende ser mais que uma apresentação da Revista SCRIPTA.

Valho-me deste "editorial", para, também, em depoimento, narrar dois momentos, curtos, mas intensamente vividos com Antonio Candido (um primeiro, a distância, por cartas, e um segundo, em uma visita), que me proporcionaram, respectivamente, amigo que assina um dos textos em "Do Afeto" e Adélia, colaboradora imprescindível a esta Edição.

Minha intenção é, em suma, reafirmar literatura como vida que costura reflexão e ação; leituras e escrita; sujeito e sociedade; crítica literária e sociológica; catarse e empenho, "grandezas" sempre reversíveis, no afã de dizer do dialético, do dialógico, como posturas inerentes à transformação do homem humano, sempre em travessia.

Nesse sentido, volto-me ao texto crítico de Candido "Jagunços mineiros de Cláudio a Guimarães Rosa" (CANDIDO, 2004), que, ainda uma vez, privilegia a dicção do professor, referenciando o ensaio como parte de um curso: "A violência habitual, como forma de comportamento ou meio de vida, 
ocorre no Brasil através de diversos tipos sociais, de que o mais conhecido é o cangaceiro da região nordestina, devido a circunstâncias já apontadas neste curso." (CANDIDO, 2004, p. 99. Destaque meu).

Já, de início, percebe-se a reiterada posição política do Crítico, ao considerar, ao lado de "forma de comportamento", a violência, no Brasil, como “ meio de vida”. Entretecem-se, portanto, nesse breve parágrafo introdutório do capítulo, o crítico, o político e o professor, sublinhando uma "escrita de vida", no trabalho do autor.

O texto em questão não será objeto aqui de outras considerações importantes que sua leitura solicitaria. Ele, como se verá, seria quase pretexto para, "trabalhando a terra", poder sorver o vinho entornado, em uma metáfora bebida no poemacanção "Fantasia", de Chico Buarque, uma das composições de Chico no CD Terra (FANTASIA, 1997), ilustrado por fotografia de Sebastião Salgado. Na referida produção de Chico, a fantasia é lugar de consolar-se de um estado de coisas, de fingir que a dor não existe, "ao som de uma canção/Então, eu te convidaria/ pra uma fantasia/ Do meu violão".

É assim que, trilhando o texto, em que se alude às mazelas de um Brasil, em percurso que leva em conta jagunços mineiros desde o século XVIII, para culminar com os jagunços rosianos, o Crítico trata da (des)ordem da lei; da co(n)fusão entre poder público e ordem privada; de (des)mandos do coronelismo. Percebe-se, no modo de ser jagunço, a realidade socio-histórica mediada e estetizada na/pela ficção, e é como se lêssemos, ainda, o Brasil da contemporaneidade.

Ao destacar o jagunço rosiano no romance, referese, então, pela segunda vez, em sua Crítica, ao princípio da 
reversibilidade, já o tendo feito no texto de 1957, "O sertão e o mundo", republicado depois, como "O homem dos avessos", textos críticos seminais para a leitura de Grande sertão: veredas. Aliás, essa reversibilidade, categoria tão cara ao crítico, lida, em um primeiríssimo momento da recepção de Grande sertão: veredas, aponta traço importante das leituras literárias de Candido: seus insights críticos originais e antecipatórios.

No ensaio crítico em questão, tendo contextualizado "os valentões" da literatura em obras cuja visão do jaguncismo reveste-se de cunho realista e pitoresco, Candido decreta um outro modo de ver a realidade jagunça, a partir de Grande sertão: veredas. $O$ romance se nos apresenta carregado de "valores simbólicos", cujo ponto de partida é, sim, a realidade física e social, não significando, no entanto, que seja obra realista.

Encontra, então, no princípio da reversibilidade que, segundo ele, parece reger a estrutura do livro, um/o ponto de partida para o deslocamento, deslizamento, do que seria precisão e realismo para o mistério e o símbolo. Argumenta com o jagunço fluido e ambíguo, cavaleiro e bandido. Desenha o jagunço no sertão como dotado de um comportamento guerreiro e aventureiro em função do meio em que vive, batalha, mas que se caracteriza também com atributos que negam essa "barbárie". Há neles uma espécie de dignidade, muitas vezes não encontrada nos cidadãos ditos civilizados, faz-nos refletir Antonio Candido.

Conclui afirmando que "há em Guimarães Rosa um ser jagunço como forma de existência, como realização ontológica no mundo do sertão" (CANDIDO, 2004, p. 113-114), acentuando que esse jagunço encarna as contradições do mundo-sertão, o que não significa, de modo algum, deformação. No jagunço apenas se atualizariam possibilidades atrofiadas do ser, porque 
o sertão o exigiria. O comportamento do jagunço rosiano é uma forma de ser no mundo; por ele, a realidade social se contamina com preocupações também metafísicas.

Nessa pauta, Candido leva seu leitor a refletir sobre o quanto cada um de nós se identifica com Riobaldo, diferentemente de outros jagunços da literatura que antecedeu à produção rosiana, e afirma: "[...] todos nós somos Riobaldo, que transcende o cunho particular do documento, para encarnar os problemas comuns da nossa humanidade, num sertão que é também o nosso espaço de vida." (CANDIDO, 2004, p. 115).

Sobre as identidades especulares - jagunços e nós mesmos -, para reiterá-las, recorre à afirmativa de Riobaldo: "Se 'o sertão é o mundo', como diz ele a certa altura do livro, não é menos certo que o jagunço somos nós." (CANDIDO, 2004, p. 115).

Terminada a leitura do ensaio, o texto continua a provocar no seu leitor inúmeras reflexões sobre consciência e humanismo, apontando um jagunço, Riobaldo, e, por projeção, cada um de nós, homem humano" construindo-se/nos na operação dialética que confronta a ciência do bem e do mal, para enfrentar o dilaceramento do eu que faz par com o dilaceramento do mundo.

$* * *$

Até aqui, intentou-se breve e "pedestre" paráfrase (como já nos alertara o Crítico quanto a esse gênero discursivo) do ensaio sobre os jagunços mineiros. De um lado, objetivou-se reiterar o humanismo como operador privilegiado das leituras de Candido, de outro, o intento foi pedir "carona", no final do referido ensaio e, por associação, chegar ao primeiro depoimento prometido no início deste texto.

Ao final de seu texto, escrito a partir de curso que lecionou, Antonio Candido, no intuito certamente de aproximar tempo e 
espaço dos estudantes aos tempos e espaços dos textos literários sobre jagunços mineiros e, mais que isso, para avivar as aulas com o afeto que lhes era peculiar, conta alguns casos sobre jagunços mineiros, bebidos em experiências de sua infância.

Conta que, no sudoeste de Minas, ainda viu pelo menos um bando de jagunços, comandado por um coronel facínora, mandante de muitas mortes, fazendeiro de fazenda fortificada e cheia de subterrâneos secretos e chefe político da vila próxima. Viu ainda o corpo baleado de um adolescente, passar ensanguentado, coberto por um lençol, em cima de uma escada na horizontal à guisa de maca, e que procedia como jagunço a mando do padrinho, um coronel.

E tempera a narrativa, literariamente, ao escrever que não chegou a alcançar os tiroteios de há vinte anos:

Mas ainda vi jagunços de renome, empreiteiros de morte ou simples valentões guarda-costas, nas suas bestas arreadas, na flama dos seus pelegos de cor, dos seus bastos prateados e dos seus dentes de ouro. E que, no entanto, sorriam com bondade aos meninos e até os passeavam no santo-antônio, para depois morrerem com o corpo crivado de balas, nas tocaias da polícia ou dos adversários. (CANDIDO, 2004, p. 123).

Como não pensar no jagunço Riobaldo? E mesmo no Damásio, de "Famigerado"? Como não pensar em cada um de nós, homem humano, em sua travessia pelo eu e mundo dilacerados? Como não exercitar o humanismo em nós, parte que somos, todos incluídos, dessa gente?

Em uma outra cidade, mais ao sul (como referido por ele), Candido se põe como contemporâneo de atrocidades cometidas por bandos armados para ajuste de contas entre políticos, aproveitando baderna de uma revolução: esperou durante pelo 
menos uma noite o assalto iminente prometido para sua cidade, enquanto seu pai, desarmado e calmo, resistia incólume, apesar de ameaçado, tendo ido buscar, a cem quilômetros, carabinas para a defesa do município, cedidas por um oficial, "cujo nome vem referido por Riobaldo", em sua narrativa. Quem seria? Quem será?

Esse tom familiar com que encerra seu texto para enfatizar o jagunço em sua humanidade - o que soa estranho, à primeira vista, a quem já se acostumou com a "megera cartesiana" a categorizar "o mundo misturado", em "bons" e "maus" - nos faz aprender com o Professor a leitura de vida que permeou todo seu trabalho crítico, que, não perdendo de vista a estética, contemplou o empenho da literatura e foi, também, nisso político.

É com ele também que pretendo encerrar este "editorial", com os dois prometidos depoimentos. Vamos a eles.

Em 2007, fico sabendo dos elogios que Candido fizera à goiabada com queijo, a que o mineiro chama "romeu e julieta", sobremesa enviada por mim aos anfitriões (Arnoni e Malu) de um almoço de confraternização. Fiquei feliz por, ainda que indiretamente, ter feito chegar até o Professor, o reconhecimento pelo prazer, pelo "gosto" que sempre me proporcionou com suas lições como Crítico. Com muita vontade de repetir essa experiência, arrisquei-me a perguntar ao Arnoni se seria excessivo ou invasivo, enviar a Candido outra sobremesa, tendo sido reforçada pelo amigo quanto a meu intento.

Da intenção ao gesto, fui rápida. Enviei-lhe, pelos amigos, a goiabada com queijo e uma "cartinha", digitada assim, em 18 de abril de 2007: 
Caríssimo Professor Antonio Candido

Esta amiga do Arnoni e da Malu foi tomada de alegria muito grande, quando soube que, no almoço de confraternização com o senhor, o casal e outros professores do seu "gadinho" (Lembra-se dessa sua carinhosa referência a seus ex-orientandos, num encontro na VNICAMP?; fiquei sabendo disso por intermédio de outra nossa grande amiga - Adélia...), o senhor gostou muito da goiabada com queijo que, a pedido da Malu, garimpei aqui nestas terras de Minas...

Assim, tendo achado uma outra goiabada, quem sabe, similar àquela, pelo menos quanto à fama, quis fazê-la chegar a suas mãos.

Titubeei na minha ousadia, mas, confessando-a ao Arnoni, fui reforçada nesse capricho pelo querido amigo.

Do desejo ao ato foi um átimo..., para não recuar.

Portanto, aí vai um romeu-e-julieta gustativo, na esperança de que, com açúcar e com afeto, possa manifestar-lhe minha admiração-grande! - e meu agradecimento - especial - pelas lições de literatura e, mais que isso, de vida que me/nos tem legado.

Receba, pois, a amizade da

Márcia

P.S - Vm lembrete: quando, numa certa noite de agosto de 2005, o senhor telefonou para a casa da Malu, para ter notícias da saúde do Arnoni, fui eu quem atendi o telefonema, e o senhor, como the é próprio, modestamente se apresentou: "- Aqui é o Antonio Candido". Impactada, dei-me a conhecer, eu mesma, como ex-orientanda do João Lafetá e do Davi, ao que ouvi: “-Então, você é minha neta!".

Ganhei o dia ...e a noite! (MORAIS, 2007, p. 1).

A resposta de Candido a esse meu gesto chegou-me em carta, cuja foto ilumina (Figura 1), ilustra este texto e cuja transcrição aqui está: 
São Paulo, 4 de junho de 2007

Cara colega Márcia Moraes:

A sra. me deu grande prazer enviando exemplares de alta qualidade do par que mereceu ser transposto em termos de ninguém menos que Skakespeare. Muito e muito obrigado. Prazer ainda maior me deu a sua carta encantadora, cheia de afetuosa naturalidade. De novo, muito e muito obrigado.

Para mim, os doces tradicionais têm um significado que vai além da fruição gustativa, porque lembram os rituais da sua fabricação sulmineira, com o dono e a dona da casa, mais os filhos, os empregados, as visitas que chegassem na hora sentados em roda para raspar os figos, "cascar" as laranjas, as goiabas, os pêcegos, os marmelos que, depois de passarem pelos 6atismos do tacho, acabariam nas latas soldadas, datadas, numeradas, armazenadas para o correr do ano. Hoje tudo isso deve ter acabado, mas para os quase nonagentários, como eu, a degustação se sublima em recapitulação afetiva do tempo perdido.

Vivi até dez anos e meio na pequena cidade de Santa Rita de Cássia, hoje apenas Cássia, que se desprendeu de Passos, no fim do século XIX em parte por obra de meu bisavô. Lá havia uma técnica de "dar o ponto" da goiabada que vinha de longe e na qual havia especialistas exigentes, como meu tio e padrinho Antonio Candido de Mello Carvalho, que na hora certa era chamado para esta delicada operação. As mulheres se afastavam e ele, concentrado, efetuava a operação decisiva... Depois fomos morar em Poços de Caldas, onde participei com parentes de lá das mesmas sessões de preparo das frutas, mas onde o ponto era dado pelas senhoras (aliás, irmãs de meu padrinho).

Mas não quero cansá-la com estas reminiscências de um mundo perdido. Quero apenas terminar pedindo-the que aceite um exemplar de meu último livro e outro de minha falecida mulher", 1 que em solteira tinha parte de seu sobrenome: Gilda de Moraes Rocha.

Muito afetuosamente,

Antonio Candido (CANDIDO, 2007, p. 1).

Os livros referidos são, respectivamente, O albatroz e o chinês (2004) e O tupi e o alaúde (2003). 


\section{Figura 1}

São Paulo, 4 de junho de 2007

Cara colega Nárcia Moraes:

A ara. me deu grande prazer enviando exemplares de alta qualidade do par que mereceu ser transposto em termos de ninguém menos que Shakespeare. Muito e muito obrigado. Prazer ainda maior ne deu a sua carta encantadora, cheia de afetuosa naturalidade. De novo, mito e muito obrigado.

Para mim, os doces tradicionais tên um sienificado que vai além da fruição gustativa, porque lembram os rituais da sua fabricação sul-mineira, con o dono e a dona da casa, nais os filhos, os empregados, as visitas que chegassen na hora sentados em roda para ragpar os figos, "cascar" as laranjas, as goiabasa, os pêcegos, os marnelos que, depois de passarem pelos batismos do tacho, acadrian nas latas soldadas, datadas, numeradas, armazenadas para o correr do ano. Hoje tudo isso deve ter ecabado, nas para os quase nonagenários, como eu, a degustação se sublima en recapitulação afetiva do tempo perdido.

Wivi até den anos e meio na pequena cidade de Santa Rita de Cássia, hoje apenas Cássia, que se desprendeu de Passos, no fim do século XIX, em parte por obra de meu hisavô. Iá havia uma técnica de "dar o ponto" da goiabada que vinha de longe e na qual havia especialistas exigentes, como meu tio e padrinho Antonio Candido de Mello Carvalho, que na hora certa era chanado para esta delicada opekação. As mineres se afastavan e ele, concentrado, efetuava a operação decisiva... Depois fomos morar fon Poços de Caldas, onde participei com parentes de lá das nesmas sessões de preparo das frutas, mas onde o ponto era dado pelas senhoras (aliás, imãs de meu padrinho).

Mas não quero cansá-la com estas reminiscências de um mundo perdido. Quero apenas terninar pedindo-lhe que aceite um exemplar de neu íltimo livro e outro de minha falecida rulher, que em solteira tinha parte do seu sonrenome: Gilda de Horaes Rocha.

$$
\begin{aligned}
& \text { Muito afeheoramente, } \\
& \text { Antonio Canoido }
\end{aligned}
$$

Fonte: Arquivo pessoal da autora.

Assim, pela memória, revisita-se a mesma cidade em que Cândido viveu sua infância até os dez anos e meio (Santa Rita de Cássia, ou simplesmente, Cássia, como ele prefere) e para onde se mudou da cidade natal, o Rio de Janeiro, aos oito meses. Reencontra-se também com Poços de Caldas (para onde se transferira seu pai), quando ele tinha dez anos e meio. 
As duas cidades referidas, no fecho do ensaio "Jagunços mineiros: de Cláudio a Guimarães Rosa", localizadas, respectivamente, no sudoeste de Minas e em outro ponto mais ao sul (CANDIDO, 2004), são, agora, nessa afetuosa carta-resposta, cenários também das reminiscências. Se, no ensaio, a narrativa tendia ao épico, na carta, é o lírico que encontra seu lugar. Um lirismo de contaminação proustiana em busca do tempo perdido, deslocando-se pelo sentido do gosto - o trincar a madeleine agora desliza da alusão à goiabada, motivo da carta-agradecimento, para a memória de doces em calda e do ponto de outra goiabada de doce lembrança, a dizer de um tempo de afeto. Afeto, marca das incursões de Candido como Professor, Crítico e Político.

O segundo depoimento prometido vai narrar uma visita ao Professor, presente que devo à amiga comum e rara, Adélia, que colabora generosamente com esta edição e que a inaugurou com comentários ao texto inédito de Candido, "Martírio e Redenção".

Convidada por ela, não saberia precisar o ano, entre 2008 e 2010, fomos visitar o Professor, em sua residência, na Alameda Joaquim Eugênio de Lima, em São Paulo.

Depois de ouvi-los sobre momentos afetuosos passados no grupo do orientador e seus ex-orientandos, sobre política - a propósito da qual Candido nos mostrava, em um misto de admiração e orgulho, em uma pilha de jornais estrangeiros, a repercussão positiva do Brasil no exterior por conta do então Presidente da República - e sobre Literatura, acentuando seu gosto e hábito de reler livros que o marcaram, fomos ao chá.

A mesa já posta nos esperava, e ele dirigiu-se à cozinha para preparar o chá "de açúcar e afeto", sorvido com sequilhos, madeleines para viagens a um tempo que viria a nos deixar tantas saudades... 
Terminado o chá, chamou-me a uma janela onde apontou, através da vidraça, para um açougue, no térreo de um prediozinho em frente, e, no andar de cima, para uma máquina de costurar. Disse-me que ali trabalhava uma senhora que, costurando até bem tarde, às noites, sustentava o filho e seus estudos. Voltandose para mim, no mesmo tratamento respeitoso da carta-resposta com que me brindou, perguntou-me: "- A senhora não acha isso edificante?".

Edificante, talvez seja essa a palavra, para terminar este texto à guisa de editorial, com base em três referências que abonam, no Houaiss, o verbete: o que conduz à virtude; o que instrui, esclarece, informa; o que constrói uma obra, individual ou coletiva, de grande importância ou alento. (EDIFICANTE, 2001).

"Alento" toma o lugar de "edificante", agora, para dizer do estado de ânimo, de coragem, necessário à travessia de um momento político desfigurado - Martírio - e que precisa viver a experiência da leitura crítica da ficção e da luta como caminhos de Redenção.

\section{Referências}

CANDIDO, Antonio. [Correspondência]. Destinatário: Márcia Marques de Morais. São Paulo, 4 jun. 2007. 1 carta datilografada. $2 \mathrm{f}$.

CANDIDO, Antonio. Formação da literatura brasileira. Momentos decisivos. 10. ed. Rio de Janeiro: Ouro Sobre Azul, 2006.

CANDIDO, Antonio. Recortes. São Paulo: Companhia das Letras, 1993. 
CANDIDO, Antonio. Jagunços mineiros de Cláudio a Guimarães Rosa. In: CANDIDO, Antonio. Vários Escritos. 4. ed. São Paulo/ Rio de Janeiro: Duas Cidades/ Ouro Sobre azul, 2004, p. 99-124.

EDIFICANTE. In: HOUAISS, Antônio. Dicionário Houaiss da língua portuguesa. Rio de Janeiro: Objetiva, 2001. p. 1099.

FANTASIA. Intérprete: Chico Buarque de Holanda. Compositor: Chico Buarque de Holanda. In: TERRA. Intérpretes: Magro, Miltinho, Ruy, Maurício Maestro, Lourenço Baeta, Fernando Gama, Choco Adnet, Lu Medeiros, Nina Pancveski, Olivia Hime, Sueli Costa, Miltom Nascimento e Chico Buarque. São Paulo: Cia. das Letras, 1997. 1 CD. Faixa 4.

MORAIS, Márcia Marques de. [Correspondência]. Destinatário: Antonio Candido de Mello e Souza. Belo Horizonte, 18 abr. 2007. 1 carta digitada. $2 \mathrm{f}$.

SAlGADO, S.; BUARQUE, C.; SARAMAGO, J. Terra. São Paulo: Companhia das Letras, 1997. 